\title{
EXTRAÇÃO DE POLPA DE UVA BRS NÚBIA UTILIZANDO ENZIMAS PECTINOLÍTICAS
}

\author{
$\underline{\text { Patrícia Pereira Dodorico }}^{1}$; Tuany Yuri Kuboyama Nogueira ${ }^{1}$; Reginaldo Teodoro de Souza ${ }^{2}$; \\ Natália Soares Janzantti ${ }^{1}$; Roberto da Silva ${ }^{1}$; Ellen Silva Lago Vanzela ${ }^{1}$ \\ (patriciapdodorico@gmail.com)
}
${ }^{1}$ Instituto de Biociências, Letras e Ciências Exatas, Universidade Estadual Paulista, Cristovão Colombo, 2265, Jardim Nazareth, 15054-000 São José do Rio Preto, São Paulo, Brasil
2 Estação Experimental de Viticultura Tropical - EMBRAPA, Jales, SP, Brazil.

Um problema que os produtores rurais enfrentam refere-se à alta perecibilidade das uvas que gera um desperdício elevado, principalmente, do excedente de produção de variedades e cultivares destinadas para consumo in natura. Para aproveitar esse excedente de produção, uma alternativa é o processamento, como a produção de polpas, sucos, passas e etc. A fim de viabilizar a produção de polpa da cultivar de mesa BRS Núbia ('Michele Palieri' x 'Arkansas 2095'), ainda pouco estudada, propõem-se um estudo de extração da polpa com uso de enzimas pectinolíticas para melhorar o rendimento da produção. As enzimas pectinolíticas atuam hidrolisando a pectina presente na casca e, consequentemente aumentam o rendimento de polpa extraída. Além de evitar o desperdício de matéria-prima essa aplicação enriquece a polpa com mais fibra e potencializa a coloração do produto, pela melhoria na extração dos compostos fenólicos, presentes, principalmente, na casca da uva. Para avaliar o efeito gerado pelas enzimas sob condições brandas de processamento, utilizou-se dois complexos enzimáticos comerciais, Pectinex Ultra Color (PUC) e Vinozym Vintage FCE (VIN), ambos fornecidos pela Novozymes, nos quais são utilizados enzimas pectinases em maior proporção pectinaliase e poligalacturonase, respectivamente. Para controle do processo, foram feitas repetições das amostras com cada enzima e também repetição do tratamento controle (submetidos às mesmas condições, porém sem adição de enzima). Além disso, foi avaliada a interação das duas enzimas nas mesmas concentrações propostas individualmente, totalizando 8 amostras. As bagas de uva BRS Núbia congeladas, foram pesadas em amostras de 50 gramas, submetidas ao descongelamento sob refrigeração e levemente trituradas com auxílio de um mixer. Foram mantidas por 50 minutos em banho de aquecimento na temperatura de $50{ }^{\circ} \mathrm{C}$ e então submetidas à agitação em intervalos de 5 minutos ao longo do período de incubação. Após o tempo determinado, cada amostra foi filtrada e prensada para separação de polpa extraída. Pesou-se o filtrado e o resíduo (casca e semente) para cálculo de rendimento. Os resultados obtidos foram: $81 \%$ de rendimento de polpa para o tratamento controle, $86 \%$ utilizando a enzima PUC, $88 \%$ com aplicação da enzima VIN e 92\% de rendimento foram alcançados com a utilização das duas enzimas simultaneamente. Portanto, observa-se que a aplicação de enzimas permite melhor extração da polpa e os dois preparados demonstraram um efeito sinérgico positivo no rendimento final.

Palavras-chave: pectinases; rendimento; uva. 